\title{
Motor Fuels and Energy - Producing Fuels Generation Based on the Processing of Municipal Solid Waste Organic Components
}

\author{
Marzhan Temirbekova ${ }^{1 *}$, Waldemar Wójcik², Vyacheslav V. Stoyak ${ }^{1}$ \\ 1 Non-profit Joint Stock Company "Almaty University of Power Engineering and Telecommunications named \\ after Gumarbek Daukeev", Baytursynuli 126/1, 050013 Almaty, Kazakhstan \\ 2 Department of Electronics and Information Technology, Lublin University of Technology, Nadbystrzycka 38a, \\ 20-618 Lublin, Poland \\ * Corresponding author's e-mail: m.temirbekova@aues.kz
}

\begin{abstract}
Municipal solid waste management and its disposal are considered one of the major challenges facing the urban communities around the world. Effective solid waste treatment involves a variety of approaches, treatment technologies and concepts to ensure the protection of public health and the environment. Waste landfill is the method most commonly used worldwide, despite all the significant environmental, health and economic consequences. Thus, alternative methods such as the municipal solid waste pretreatment, fermentation, ethanol fermentation and anaerobic fermentation have been the focus of heightened attention. Using these methods, an alcohol-containing liquid was obtained from $1.5 \mathrm{~kg}$ of the organic fraction of municipal solid waste (OFMSW), which had an ethanol percentage of $97.45 \%$. Consequently, if properly managed and used, municipal solid waste can be a viable source of energy rather than a source of pollution.
\end{abstract}

Keywords: municipal solid waste, bioethanol, fermentation, ethanol fermentation.

\section{INTRODUCTION}

There is growing interest in the ethanol production from abundant and low-cost waste, for example, agricultural waste [Kim and Dale, 2004; Reijnders, 2008; Sarkar et al., 2012], municipal solid waste and food waste [Ma et al., 2017; Yan et al., 2011] in the modern world. Among these low-cost substrates, municipal solid waste is an abundant raw material with zero cost; due to the excessive concentration of population in cities and the emergence of metropolises, the waste situation is becoming acute. In terms of municipal solid waste disposal methods, waste landfilling is characterized by the maximum practical distribution in the world practice, but judging the by experience of waste management of the leading countries of the world, disposal of wastes using this method at the present time becomes unpromising, since it pollutes the territories and groundwater [Nozhevnikova, 2016].
It should be noted that various factors, including culture, location, weather conditions, as well as the degree of economy and development of a given society, affect the composition of municipal solid waste [Alavi Moghadam et al., 2009]. Solid waste generated in developing countries every year, contains $40-88 \%$ food waste [Sharholy et al., 2007; Talyan et al., 2008; Yousuf and Rahman, 2007], indicating that the organic fraction of the waste consists mainly of starch, lignocellulose, and lipids. Starch and lignocellulose have a high potential for conversion to ethanol, while other organic fractions such as lipids cannot be converted to ethanol, but these biodegradable components can be converted to biogas by anaerobic fermentation. Pretreatment can increase the bioavailability of lignocellulose by the cellulase. Among the various methods, hydrothermal pretreatment reduces the formation of fermentation inhibitors, which are formed mainly by sugar degradation. Hydrothermal pretreatment is an 
environmentally friendly process because it uses no chemicals; this treatment removes most of the hemicellulose and improves the enzyme availability for cellulose [Taherzadeh and Karimi, 2008].

\section{MATERIALS AND METHODS}

Fractional models of organic components, which were collected in accordance with the approximate chemical composition of municipal solid waste, were used in this qualitative research implementation, as well as a sample with organic components from the municipal solid waste landfill of the "Tartyp" Joint Stock Company (JSC), Almaty. A total of 5 fractions with various composition and mass were collected:

- Natural sample from the municipal solid waste landfill of Almaty $(1500 \mathrm{~g})$;

- lipids containing model fraction (509 g);

- Cellulose containing model fraction (850 g);

- Carbohydrates containing model fraction (900 g);

- Combined fraction (cellulose - $850 \mathrm{~g}$, carbohydrates $-900 \mathrm{~g}$, lipids $-500 \mathrm{~g}$ ).

The experimental procedure consists of the following main stages: preliminary hydrothermal treatment, enzymatic hydrolysis (amylase, glucavamarin, amylosubtiline, cellulase), ethanol fermentation (alcohol yeast) of the liquid waste fraction.

The sample was formed, moisture content and $\mathrm{pH}$ were determined, and then it was hydrothermally treated at $120^{\circ} \mathrm{C}$ for 4 hours. Qualitative reactions for the presence of starch and glucose were carried out after hydration, then the samples were separated into liquid and solid fractions and the fermentation began. Afterwards, 1.5 gamylosubtilin was added to the liquid part of the sample for 1.5 hours at $65^{\circ} \mathrm{C}$, then $2 \mathrm{~g}$ of glucavamarine for 1.5 hours at $50^{\circ} \mathrm{C}$. Subsequently, $2 \mathrm{~g}$ of cellulase was added to the solid part of the sample for 1.5 hours at $50^{\circ} \mathrm{C}$ and $1.5 \mathrm{~g}$ of amylase at $65^{\circ} \mathrm{C}$ for 1.5 hours. The fermentation was followed by ethanol fermentation, for this purpose alcoholic yeast $(15 \mathrm{~g})$ is added to the liquid part for ethanol production [Mahmoodia et al., 2018].

\section{RESULTS AND DISCUSSION}

In the qualitative research, liquids with various volumes were obtained from each model sample after hydrothermal pretreatment, fermentation, and ethanol fermentation.

The obtained samples with liquids were analyzed by Gas chromatography-mass spectrometry (GC-MS) (Agilen 7890A $\backslash 5975 \mathrm{C}$ ) to determine the chemical composition. Passing through the chromatograph, the samples are separated into components, and the mass spectrometer is responsible for their identification and analysis. This detection mode is highly accurate, its essence is to record readings not over the total volume of the incoming ion current, but over the maximum ions for the supposed molecules, and curves of the time dependent signal are plotted. The chromatogram is a graphical representation of the detector signal used to measure the concentration of substances in the eluate, from the time of the mobile phase. Schematically, chromatograms are the Gaussian peaks sequence on a baseline.

The analysis of the model combined sample detected the presence of the following components in the composition: ethanol, 1-butanol, 3-methyl, propanoic acid, 2-methyl, oxime, methoxy-phenyl, and $1-\alpha$ - terpineol. Table 2 provides the data on retention time, peak areas and components, abundance and concentration of these substances.

In accordance with Table 2, a graph of gas chromatography-mass spectrometry was provided, which shows the result of recording the time dependent abundance at the column outlet. The concentration of each peak in percent is calculated from the peak area.

Table 3 shows the results of gas chromatography analysis of the lipids containing sample, with the following composition of this sample: ethanol, 1-butanol, 3-methyl, propanoic acid, 2-methyl, butanoic acid, butyric acid, 3-methyl, oxime,

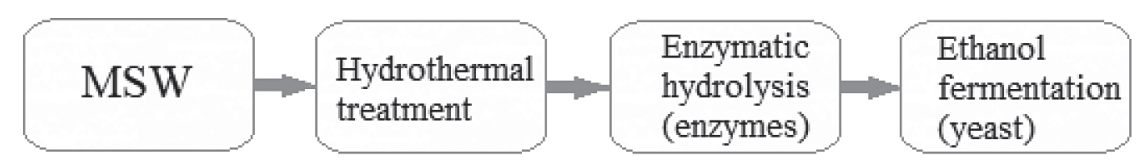

Figure 1. Experiment sequence diagram 
Table 1. Ethanol fermentation results

\begin{tabular}{|c|l|c|}
\hline No. & \multicolumn{1}{|c|}{ Sample Name and mass $(\mathrm{g})$} & $\begin{array}{c}\text { The amount of liquid after ethanol } \\
\text { fermentation }(\mathrm{ml})\end{array}$ \\
\hline 1. & Natural sample from the municipal solid waste landfill of Almaty $(1500 \mathrm{~g})$ & $135 \mathrm{ml}$ \\
\hline 2. & Lipids containing model fraction $(509 \mathrm{~g})$ & $80 \mathrm{ml}$ \\
\hline 3. & Cellulose containing model fraction $(850 \mathrm{~g})$ & $117 \mathrm{ml}$ \\
\hline 4. & Carbohydrates containing model fraction $(900 \mathrm{~g})$ & $95 \mathrm{ml}$ \\
\hline 5. & Combined fraction (cellulose $-850 \mathrm{~g}$, carbohydrates $-900 \mathrm{~g}$, lipids $-500 \mathrm{~g})$ & $162 \mathrm{ml}$ \\
\hline
\end{tabular}

Table 2. Components of the combined sample

\begin{tabular}{|c|c|c|l|c|c|}
\hline Peak No. & Ret time $(\mathrm{min})$ & Area $(\mathrm{S})$ & \multicolumn{1}{|c|}{ Component } & Abundance & $\%$ \\
\hline 1 & 1,681 & 4237936015 & Ethanol & 94 & 95.8 \\
\hline 2 & 3,978 & 151571481 & 1-Butanol, 3-methyl- & 62 & 3.4 \\
\hline 3 & 6,389 & 3217162 & Propanoic acid, 2-methyl- & 73 & 0.1 \\
\hline 4 & 9,499 & 28243644 & Oxime-, methoxy-phenyl-_ & 77 & 0.6 \\
\hline 5 & 17,185 & 2258941 & L-a-Terpineol & 71 & 0.1 \\
\hline
\end{tabular}

methoxy-phenyl, pyrazine, tetramethyl, phenylethyl alcohol, triethyl citrate, phthalic acid, and butyl hex-3-yl ester. The retention time required to elute the substance corresponds to the time of the peak maximum appearance on the chromatogram, the peak areas, the abundance or signal of the detector, as well as the data on the substances percentage in the sample.

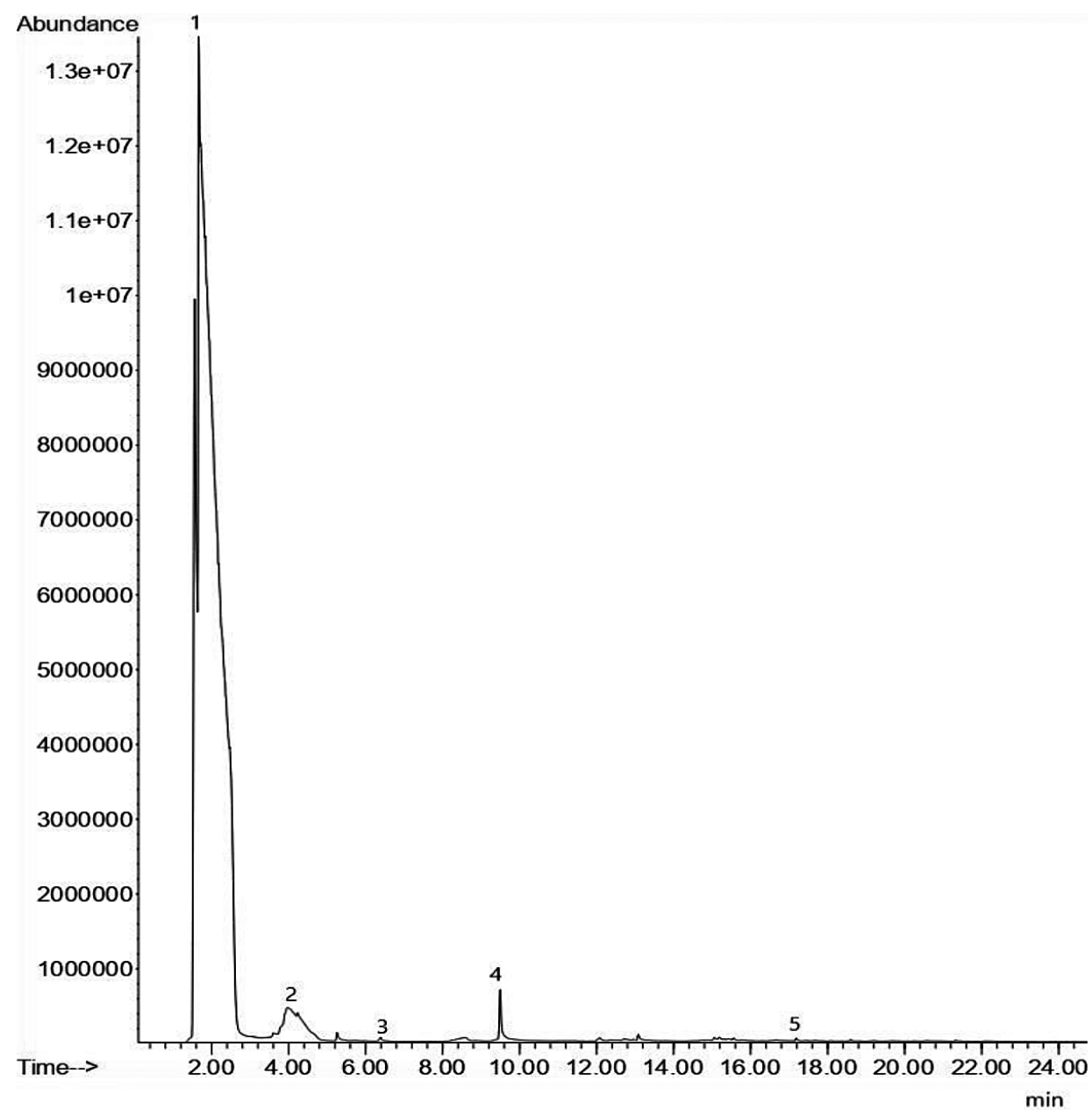

Figure 2. Chromatogram of the time (time) dependent components concentration of the combined sample (abundance) 
Table 3. Concentration of the lipids containing sample components

\begin{tabular}{|c|c|c|l|c|c|}
\hline $\begin{array}{c}\text { Peak } \\
\text { No. }\end{array}$ & Ret time (min) & Area (S) & \multicolumn{1}{|c|}{ Component } & Abundance & $\%$ \\
\hline 1 & 1,733 & 2084267735 & Ethanol & 93 & 93.85 \\
\hline 2 & 3,974 & 66427254 & 1-Butanol, 3-methyl- & 81 & 2.99 \\
\hline 3 & 6,623 & 3468608 & Propanoic acid, 2-methyl- & 83 & 0.16 \\
\hline 4 & 7,407 & 4610257 & Butanoic acid & 77 & 0.21 \\
\hline 5 & 8,522 & 10123063 & Butanoic acid, 3-methyl- & 63 & 0.46 \\
\hline 6 & 9,576 & 31078988 & Oxime-, methoxy-phenyl-_ & 85 & 1.40 \\
\hline 7 & 15,176 & 9813476 & Pyrazine, tetramethyl- & 80 & 0.44 \\
\hline 8 & 16,477 & 9109129 & Phenylethyl Alcohol & 74 & 0.41 \\
\hline 9 & 27,674 & 1155125 & Triethyl citrate & 75 & 0.05 \\
\hline 10 & 33,817 & 909606 & Phthalic acid, butyl hex-3-yl ester & 77 & 0.04 \\
\hline
\end{tabular}

The lipid sample contains characteristic aromatic heterocyclic organic compounds in its component composition, such as Pyrazine, monobasic short-chain saturated fatty acids (Butyric acid), and monohydric phenylethyl alcohol contained in essential oils, which indicates the reliability of the analysis method.

According to the data in Table 3, the provided chromatogram clearly shows the dependences of the components abundance and the retention time (the time required for substance elution corresponds to the time of the maximum peak appearance in the chromatogram). Each peak with the corresponding number reflects the component presented in the table.

The results of the mass spectrometry analysis of the sample with cellulose detected the following components concentrations: ethanol, 1-butanol, 3-methyl oxime, methoxy-phenyl, and dibutyl phthalate. This sample showed the lowest percentage of ethanol, compared to the others, since cellulose contains ligninocellulose in its

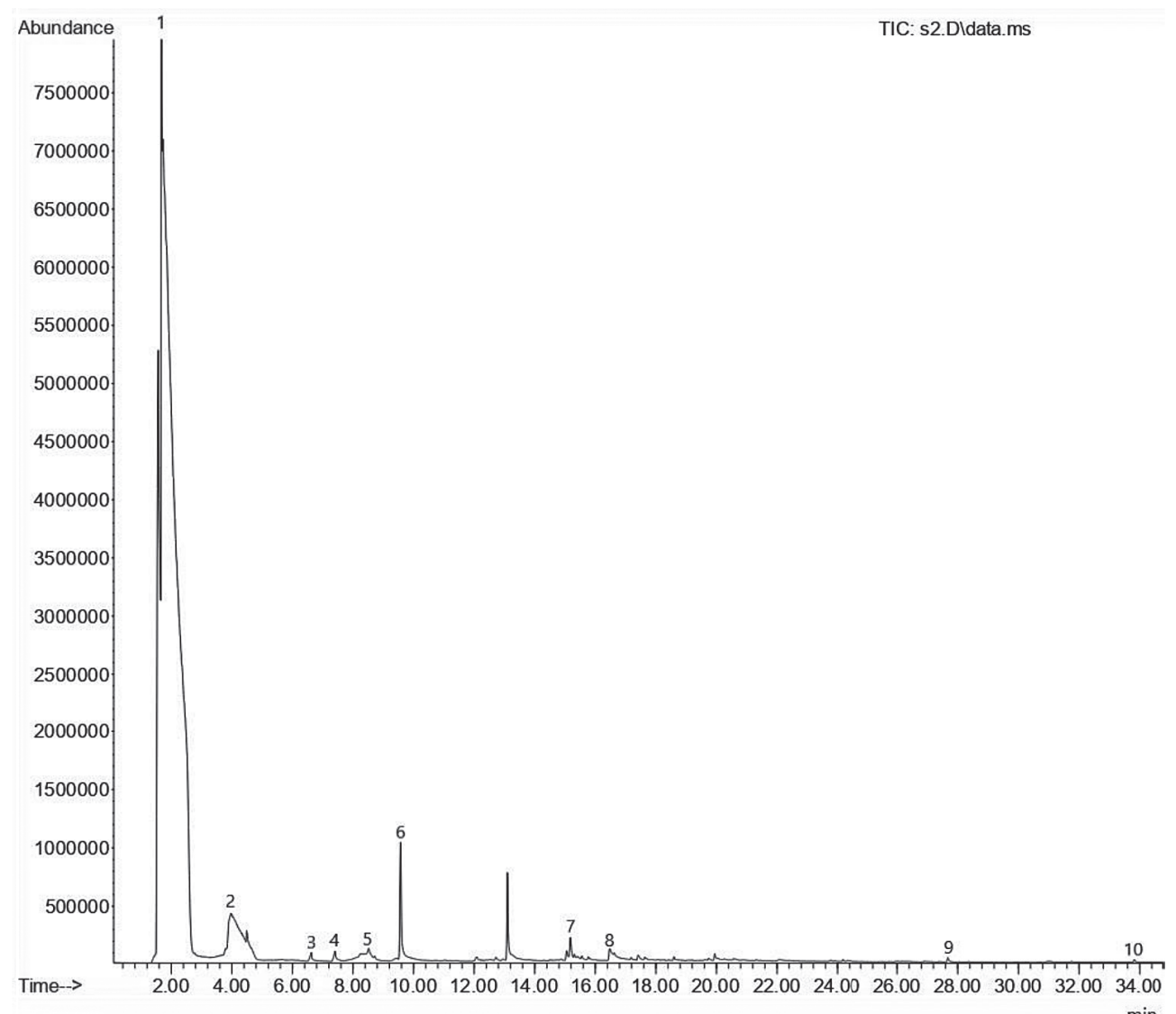

Figure 3. Graph of the lipids containing sample components ratio 
Table 4. Concentration of cellulose containing sample components

\begin{tabular}{|c|c|c|l|c|c|}
\hline Peak No. & Ret time $(\mathrm{min})$ & Area $(\mathrm{S})$ & \multicolumn{1}{|c|}{ Component } & Abundance & $\%$ \\
\hline 1 & 1,718 & 2571350344 & Ethanol & 92 & 90.84 \\
\hline 2 & 3,986 & 201445006 & 1-Butanol, 3-methyl- & 81 & 7.12 \\
\hline 3 & 9,513 & 37545433 & Oxime-, methoxy-phenyl-_ & 79 & 1.33 \\
\hline 4 & 33,818 & 20161521 & Dibutyl phthalate & 96 & 0.71 \\
\hline
\end{tabular}

composition, which has a dense structure. Lignin is a complex molecule consisting of phenylpropane units linked in a three-dimensional structure, which is especially difficult to biodegrade, the higher the lignin fraction, the higher the chemical and enzymatic degradation resistance.

Figure 4 shows the graph of the time (peak) dependent detector signal (substance abundance) in the cellulose containing sample. Each component corresponds to the time and peak registering the detector response.

In the sample with carbohydrates, after analysis on the gas chromatograph, the content of ethanol (96.27\%) was detected; the sample also contains such components as: 1-butanol, 3-methyl, oxime, and methoxy-phenyl.

The chromatogram of the carbohydrates containing model sample is shown in Figure 5, where each component corresponds to the peak number and retention time.

A natural sample from the municipal waste disposal landfill of Almaty, after a qualitative research with fermentation, showed the highest ethanol content of $97.45 \%$ compared to other samples, as well as such substances as oxime-, methoxy-phenyl, ethyl 2- (5-methyl-5-vinyltetrahydrofuran-2 -yl), propan-2-yl carbonate, pyrazine, tetramethyl, 2h-pyran-3-ol, 6-ethenyltetrahydro-2,2,6-trimethyl, and $\alpha$-terpineol. Table 6 shows the peak time, the area and the abundance of each component, and the concentrations of these substances.

The chromatogram of the substances abundance, the peaks area and the retention time of the sample with the organic fraction of the municipal solid waste landfill in Almaty is shown in Figure 6.

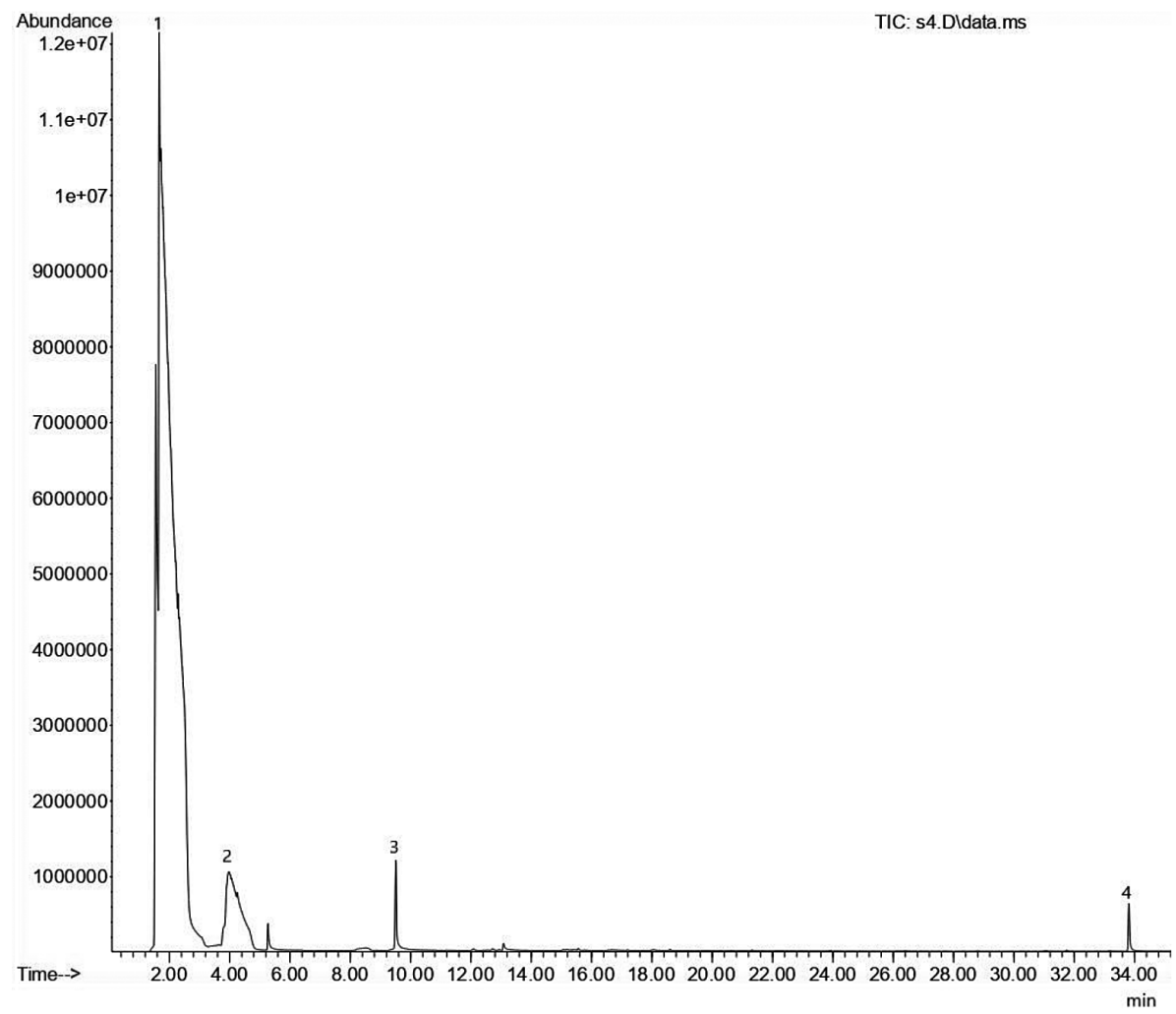

Figure 4. Chromatogram of the dependence of the substances concentration and the time of the cellulose containing sample 
Table 5. The carbohydrates containing sample components concentration

\begin{tabular}{|c|c|c|l|c|c|}
\hline Peak \# & Ret Time $(\min )$ & Area(S) & \multicolumn{1}{|c|}{ Component } & Abundance & $\%$ \\
\hline 1 & 1,715 & 3312233598 & Ethanol & 93 & 96.28 \\
\hline 2 & 4,215 & 88291610 & 1-Butanol, 3-methyl- & 69 & 2.57 \\
\hline 3 & 9,497 & 39044278 & Oxime-, methoxy-phenyl & 79 & 1.15 \\
\hline
\end{tabular}

\section{CONCLUSIONS}

Ethanol is present in large amounts in all analyzed samples; butanol is also present in the composition, which indicates that pretreatment, fermentation and ethanol fermentation had a positive effect on the bioethanol production. The ethanol concentration in a natural sample obtained from the landfill has the highest rate of $97.45 \%$, compared to the others, which indicates that the natural sample of municipal solid waste from the landfill in Almaty has the greatest potential for its production. Model samples with different homogeneous and heterogeneous composition and also a natural sample from the landfill were selected to assess the differences in the degree of fermentation and ethanol concentration. On the basis of the results, it can be judged that the combination of components and a heterogeneous composition like in the natural waste sample, may contribute to increase the ethanol concentration and its other isomers. Probably, the mixed raw materials contain more components and the effect of enzymes improves their bioavailability and prepares them for ethanol fermentation, and pretreatment promotes the cleavage of lignin and

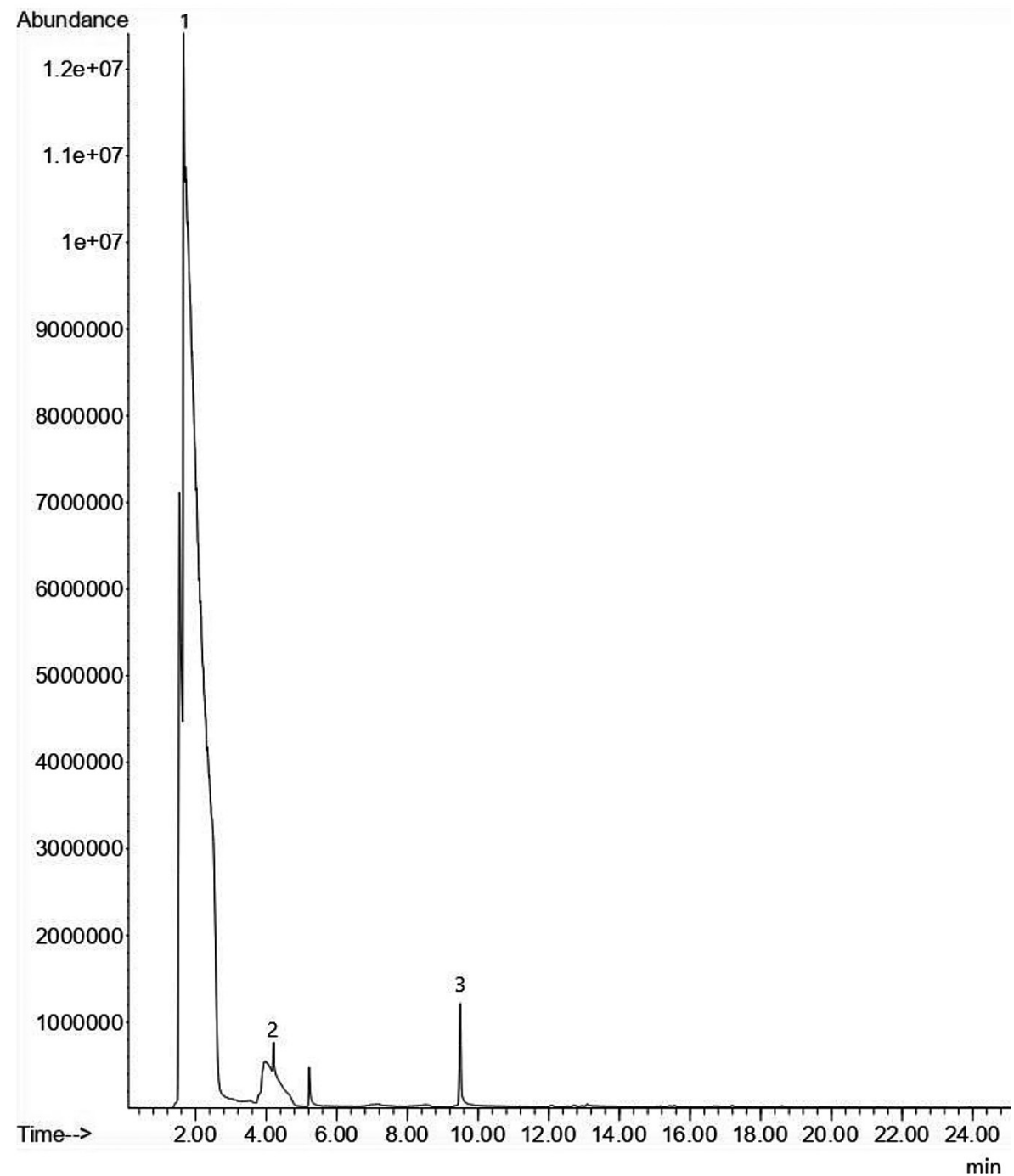

Figure 5. Graph of the time dependent carbohydrate containing sample components concentration 
Table 6. The natural sample components concentration obtained from the municipal solid waste landfill of the "Tartyp" Joint Stock Company (JSC) in Almaty:

\begin{tabular}{|c|c|c|l|c|c|}
\hline Peak No. & Ret time (min) & Area(S) & \multicolumn{1}{|c|}{ Component } & Abundance & \multicolumn{1}{c|}{ \% } \\
\hline 1 & 1,731 & 2339904556 & Ethanol & 97.45 \\
\hline 2 & 9,559 & 44417720 & Oxime-, methoxy-phenyl-_ & 80 \\
\hline 3 & 14,317 & 5705926 & $\begin{array}{l}\text { Ethyl 2-(5-methyl-5-vinyltetrahydrofuran-2-yl)propan- } \\
\text { 2-yl carbonate }\end{array}$ & 86 \\
\hline 4 & 15,18 & 7123396 & Pyrazine, tetramethyl- & 81 \\
\hline 5 & 16,779 & 2328081 & 2H-Pyran-3-ol, 6-ethenyltetrahydro-2,2,6-trimethyl- & 6.30 \\
\hline 6 & 17,185 & 1557327 & a-Terpineol & 0.10 \\
\hline
\end{tabular}

lignin containing cellulose, which are present in many components of municipal solid waste.

The experiment was carried out under laboratory conditions with small masses of samples, after obtaining ethanol, on an industrial scale, there will be a large amount of residues of the solid part of the waste, which can be exposed by the method of anaerobic fermentation for methane production and its further use as an alternative source of energy, which in its the queue has a good economic benefit, since the waste raw materials have zero cost. Therefore, high concentration Ethanol, as well as - biogas (methane) can be produced jointly from organic components of municipal

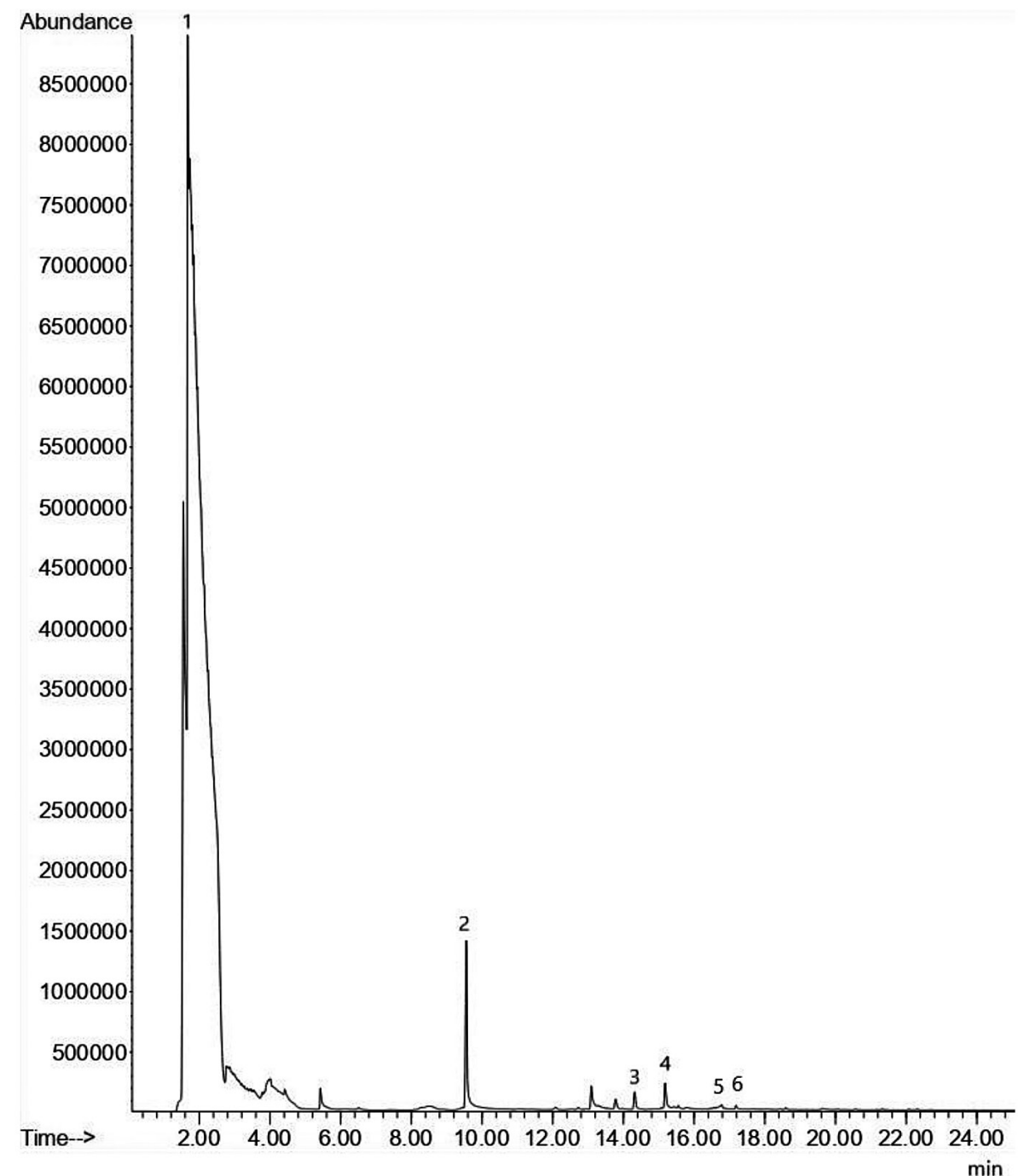

Figure 6. Graph of the natural sample components concentration obtained from the municipal solid waste landfill of the "Tartyp" Joint Stock Company (JSC) in Almaty 
solid waste. In addition to the direct economic benefit, the production of biogas and bioethanol from waste can:

- reduce the waste sites volume;

- reduce greenhouse gas emissions;

- reduce the natural gas consumption.

It is necessary to develop alternative energy to support the global efforts to reduce the greenhouse gas emissions and improve the climate by producing ethanol and methane from the organic fraction of municipal solid waste.

\section{REFERENCES}

1. Alavi Moghadam, M.R., Mokhtarani, N., Mokhtarani, B., 2009. Municipal solid waste management in Rasht City, Iran. Waste Manage. 29(1), 485-489.

2. Kim, S., Dale, B.E., 2004. Global potential bioethanol production from wasted crops and crop residues. Biomass Bioenergy 26 (4), 361-375.

3. Ma, Y., Cai, W., Liu, Y., 2017. An integrated engineering system for maximizing bioenergy production from food waste. Appl. Energy 206(C), 83-89.

4. Mahmoodia P., Karimi K., Taherzadeh M.J., 2018. Hydrothermal processing as pretreatment for efficient production of ethanol and biogas from municipal solid waste Bioresource Technology, 261,
166-175.

5. Nozhevnikova A.N. 2016. Biotechnology and microbiology of the municipal solid waste anaerobic processing, Moscow.

6. Reijnders, L., 2008. Ethanol production from crop residues and soil organic carbon. Resour. Conserv. Recycl. 52(4), 653-658.

7. Sarkar, N., Ghosh, S.K., Bannerjee, S., Aikat, K., 2012. Bioethanol production from agricultural wastes: an overview. Renewable Energy 37(1), 19-27.

8. Sharholy, M., Ahmad, K., Vaishya, R., Gupta, R., 2007. Municipal solid waste characteristics and management in Allahabad, India. Waste Manage. 27(4), 490-496.

9. Taherzadeh, M.J., Karimi, K., 2008. Pretreatment of lignocellulosic wastes to improve ethanol and biogas production: a review. Int. J. Mol. Sci. 9.

10. Talyan, V., Dahiya, R., Sreekrishnan, T., 2008. State of municipal solid waste management in Delhi, the capital of India. Waste Manage. 28(7), 1276-1287.

11. Yan, S., Li, J., Chen, X., Wu, J., Wang, P., Ye, J., Yao, J., 2011. Enzymatical hydrolysis of food waste and ethanol production from the hydrolysate. Renewable Energy 36(4).

12. Yousuf, T.B., Rahman, M., 2007. Monitoring quantity and characteristics of municipal solid waste in Dhaka City. Environ. Monit. Assess. 135(1), 3-11. 